\title{
Author Correction: Prediction of Response to Neoadjuvant Chemoradiotherapy by MRI-Based Machine Learning Texture Analysis in Rectal Cancer Patients
}

\author{
Sajad P. Shayesteh ${ }^{1}$ - Afsaneh Alikhassi ${ }^{2}$. Farshid Farhan ${ }^{3,4} \cdot$ Reza Ghalehtaki $^{4}$ - Masume Soltanabadi ${ }^{5}$. \\ Peiman Haddad ${ }^{3,4}$. Ahmad Bitarafan-Rajabi ${ }^{6,7}$
}

Published online: 11 December 2019

(C) Springer Science+Business Media, LLC, part of Springer Nature 2019

\section{Author Correction: Journal of Gastrointestinal Cancer https://doi.org/10.1007/s12029-019-00291-0}

The original version of this article unfortunately contained a mistake. In the author group section, the correct name of the fourth author is "Reza Ghalehtaki."

The authors apologize for this oversight and for any confusion it may have caused.

Publisher's Note Springer Nature remains neutral with regard to jurisdictional claims in published maps and institutional affiliations.

The online version of the original article can be found at https://oi.org/ 10.1007/s12029-019-00291-0

Peiman Haddad

haddad@tums.ac.ir

$\triangle \quad$ Ahmad Bitarafan-Rajabi

bitarafan@hotmail.com

Sajad P. Shayesteh

shayeste_sajad@yahoo.com

1 Department of Physiology, Pharmacology and Medical Physics, Faculty of Medicine, Alborz University of Medical Sciences, Karaj, Iran

2 Department of Radiology, Cancer Institute of Iran, Tehran University of Medical Sciences, Tehran, Iran
3 Radiation Oncology Research Center, Cancer Institute, Tehran University of Medical Sciences, Tehran, Iran

4 Radiation Oncology Department, Cancer Institute, Tehran University of Medical Sciences, Tehran, Iran

5 Department of Nuclear Medicine, Faculty of Medicine, Shahrekord University of Medical Sciences, Shahrekord, Chaharmahal and Bakhtiari, Iran

6 Cardiovascular Intervention Research Center, Rajaie Cardiovascular Medical and Research Center, Iran University of Medical Sciences, Tehran, Iran

7 Echocardiography Research Center, Rajaie Cardiovascular Medical and Research Center, Iran University of Medical Sciences, Tehran, Iran 